\title{
Representações sociais da autonomia do enfermeiro para acadêmicos de enfermagem
}

\author{
Social representations of nurses' autonomy for nursing academics
}

\author{
Representaciones sociales de la autonomía del enfermero con alumnos \\ de pregrado en enfermería
}

\section{Diego Bonfante Mota ${ }^{1}$, Antonio Marcos Tosoli Gomes ${ }^{2}{ }^{\circledR}$, Aline Cerqueira Santos Santana da Silva ${ }^{3}$, Raquel de Souza Ramos ${ }^{4}$, Virgínia Paiva Figueiredo Nogueira ${ }^{5}$, Luísa dos Santos Belém ${ }^{6}$}

Histórico

Recibido:

23 de febrero de 2018

Aceptado:

19 de abril de 2018

1 Enfermeiro. Polo Universitário de Rio das Ostras da Universidade Federal Fluminense, Rio de Janeiro, Brasil.

2 Pós-doutor em Enfermagem. Professor Titular da Faculdade de Enfermagem da Universidade do Estado do Rio de Janeiro. Rio de Janeiro, Brasil.

3 Doutora em Enfermagem. Professora Adjunta do Pólo de Rio das Ostras da Faculdade de Enfermagem da Universidade Federal Fluminense, Rio de Janeiro, Brasil.

4 Doutora em Enfermagem. Enfermeira do Instituto Nacional do Câncer e do Hospital Universitário Pedro Ernesto, Rio de Janeiro, Brasil. Correspondencia E-mail: kakelramos@gmail.com

5 Doutoranda em Enfermagem da Universidade do Estado do Rio de Janeiro, Rio de Janeiro, Brasil.

6 Enfermeira. Residente de Enfermagem do Hospital Universitário Antonio Pedro, Rio de Janeiro, Brasil. Introdução: A autonomia profissional corresponde à realização de ações de enfermagem por meio da utilização de habilidades, conhecimentos e atitudes para tomar decisões e resolver situações no seu espaço de atuação. Objetivo: analisar as representações sociais da autonomia do enfermeiro para acadêmicos do último período de graduação em enfermagem de uma universidade federal. Materiais e Métodos: Estudo qualitativo, descritivo, exploratório delineado a partir da teoria das representações sociais em sua abordagem processual, realizada com 20 acadêmicos de enfermagem no último período de uma universidade federal localizada no estado do Rio de Janeiro. A coleta de dados se deu através de entrevistas semiestruturadas e a análise das produções discursivas pelo método de análise de conteúdo. Resultados: Foram construídas cinco categorias de análise. Discussão: Verificou-se que as representações sociais da autonomia profissional dos discentes de enfermagem encontram-se em processo de construção, tendo por fundamento o gerenciamento, as práticas invasivas e a consulta de enfermagem. A autonomia também se relaciona ao cuidado predominantemente individual. Conclusões: A representação da autonomia profissional está vinculada a tecnologias atuais e a dimensões históricas da profissão, bem como a necessidade de novos estudos para a compreensão do fenômeno.

Palavras chave: Educação em Enfermagem; Percepção Social; Autonomia Profissional; Cuidados de Enfermagem.

Abstract

Introduction: Professional autonomy corresponds to the performance of nursing actions by using skills, knowledge, and attitudes to make decisions and solve situations in their work setting. Objective: to analyze the social representations of the nurse's autonomy for academics of the final graduation period in nursing from a federal university. Materials and Methods: This was a qualitative, descriptive, exploratory study defined from the theory of social representations in its procedural approach, carried out with 20 nursing academics during their last period of a federal university located in the state of Rio de Janeiro, Brazil. Data was collected through semi-structured interviews and discursive productions were analyzed through the content analysis method. Results: The study constructed five analysis categories. Discussion: It was verified that the social representations of professional autonomy of nursing students are in the construction process, based on management, invasive practices, and nursing consultation. Autonomy is also related to predominantly individual care. Conclusions: The representation of professional autonomy is linked to current technologies and to the historical dimensions of the profession, as well as to the need for new studies to understand the phenomena.

Key words: Education, Nursing; Social Perception; Professional Autonomy; Nursing Care.

Resumen

Introducción: La autonomía profesional corresponde a la realización de acciones de enfermería por medio de la utilización de habilidades, conocimientos y actitudes para tomar decisiones y resolver situaciones en su espacio de actuación. Objetivo: analizar las representaciones sociales de la autonomía del enfermero con estudiantes de último semestre de enfermería de una universidad federal. Materiales y Métodos: Estudio cualitativo, descriptivo, exploratorio, diseñado a partir de la teoría de las representaciones sociales con enfoque procesal, realizado con 20 alumnos de último semestre de una universidad federal localizada en el estado de Rio de Janeiro. La recolección de datos se dio a través de entrevistas semiestructuradas y el análisis de las producciones discursivas por el método de análisis de contenido. Resultados: Fueron construidas cinco categorías de análisis. Discusión: Se verificó que las representaciones sociales de la autonomía profesional de los alumnos de enfermería se encuentran en proceso de construcción teniendo por base el gerenciamiento, las prácticas invasivas y la consulta de enfermería. La autonomía también se relaciona al cuidado predominantemente individual. Conclusiones: La representación de la autonomía profesional está vinculada a las tecnologías actuales y las dimensiones históricas de la profesión, así como la necesidad de nuevos estudios para la comprensión del fenómeno.

Palabras clave: Educación en Enfermería; Percepción Social; Autonomía Profesional; Atención de Enfermería.

Como citar este artigo: Mota DB, Gomes AMT, Silva ACSS, Ramos RS, Nogueira VPF, Belém LS. Representações sociais da autonomia do enfermeiro para acadêmicos de enfermagem. Rev Cuid. 2018; 9(2): 2215-32. http://dx.doi.org/10.15649/cuidarte.v9i2.528

(c) (1) (9) 2018 Universidad de Santander. Este es un artículo de acceso abierto, distribuido bajo los términos de la licencia Creative Commons Attribution (CC BY-NC 4.0), que permite el uso ilimitado, distribución y reproducción en cualquier medio, siempre que el autor original y la fuente sean debidamente citados. 


\section{INTRODUÇÃO}

Ao observar a evolução histórica do ensino em enfermagem são evidentes inúmeros desafios em diferentes épocas e circunstâncias. Os currículos da graduação de enfermagem precisam contemplar o maior número possível de conhecimentos sobre técnicas de cuidado pelos profissionais. Por outro lado, em algumas Instituições de Ensino Superior (IES), estes ainda se encontram distantes de uma reflexão crítica. Essa compreensão mostra que embora a graduação seja abrangente, ainda contém alguns empecilhos que prejudicam a plenitude da autonomia profissional ${ }^{1}$.

A profissão, com toda evolução tecnológica, passa por inovações como a Sistematização da Assistência em Enfermagem (SAE) que é apontada como um dos instrumentos capazes de garantir melhorias no desempenho da equipe de enfermagem para a assistência prestada e garantir a autonomia desta equipe, além de estudos que garantem melhorias na execução das tarefas exigidas nos diferentes campos de atuação ${ }^{2}$. A partir deste contexto, deve ser constante a busca dos discentes e docentes pelo aprendizado e descoberta desta tecnologia, que pode viabilizar a conquista de um grau maior de autonomia perante a sociedade em sua carreira profissional.

O significado da palavra autonomia pode ser caracterizado como "qualidade ou estado autônomo, liberdade moral e intelectual"3. Logo, seu conceito está como o ato de ter liberdade para tomar decisões advindas do seu intelecto e moral, ou seja, autogovernar-se. Quanto à autonomia profissional de enfermagem e seu conceito, destaca-se que correspondem à realização de ações de enfermagem por meio da utilização de habilidades, conhecimentos e atitudes para tomar decisões e resolver situações no seu espaço de atuação ${ }^{4}$. Passam a ser compreensíveis, então, as influências dos ensinos teóricos e práticos para garantirem, de maneira mais autônoma, as habilidades dos acadêmicos, que na maioria das vezes irão refletir sobre atitudes a serem tomadas em seu campo de atuação profissional. Esta, por sua vez, poderá ser embasada em conhecimentos e experiências adquiridas pelo enfermeiro em suas vivencias dentro do contexto universitário.

A problemática da autonomia profissional em enfermagem para os alunos de graduação se apresenta como importante devido ao fato de que esta questão influenciará, ao menos em parte, no modo como o profissional se posicionará sobre isto no futuro, bem como a sua visão acerca da própria profissão e do seu papel na equipe de saúde, nas distintas instituições sanitárias onde trabalha, nos diferentes níveis de atenção e na explicitação do seu papel próprio diante da sociedade. Deve-se destacar, ainda, que a autonomia profissional do enfermeiro como objeto de pesquisa ou como prática sócioprofissional mostra-se de grande complexidade, tendo em vista, dentre outras coisas, a área de interface entre as ciências biomédicas, humanas e sociais que a profissão possui e a necessidade de construção constante de todo um arcabouço teórico, metodológico e profissional que dê conta deste desafio.

Frente a este contexto, destaca-se como objetivo deste artigo analisar as representações sociais da autonomia do enfermeiro para acadêmicos do último período de graduação em enfermagem de uma universidade federal. 


\section{MATERIAIS E METTODOS}

O presente projeto tem metodologia de pesquisa qualitativa, exploratória, descritiva que foi elaborada através da teoria das representações sociais em sua abordagem processual. Ao utilizar a abordagem processual desenvolvida por Jodelet $^{5}$, no contexto das representações sociais, este estudo propõe captar os valores e as ideias presentes nos discursos e nas vivências do grupo estudado com relação ao objeto de representação. Tenta-se, então, captar os conteúdos das representações sociais especialmente através da linguagem ${ }^{5}$.

Os participantes da presente pesquisa foram os acadêmicos de enfermagem que estão devidamente matriculados cursando o último período de faculdade em uma universidade federal. Dos 24 discentes presentes na turma deste período foram entrevistados 20, o que é um número crível para trabalhos que envolvem representação social na perspectiva da abordagem processual $^{6,7}$. Foram usados como critérios de inclusão discentes matriculados e cursando o último período da graduação de enfermagem no cenário do projeto.

Acordado com a Resolução 466/2012 do Conselho Nacional de Saúde que dispõe os aspectos éticos e legais para pesquisas em humanos, o estudo foi submetido e aprovado pelo Comitê de Ética em pesquisa, sob o número CAAE é 37502914.8.0000.5243. Os participantes foram convidados através do Termo de Consentimento Livre e Esclarecido e a participação foi voluntária.

A técnica utilizada para coleta de dados foi a entrevista semiestruturada com a finalidade de nortear e captar, com maior clareza e sem interromper, as informações no diálogo com o entrevistado. Considera-se a técnica capaz de identificar as representações sociais dos acadêmicos de enfermagem do último período da universidade escolhida. A elaboração de perguntas para pesquisas qualitativas é uma atividade que exige bastante atenção e perspicácia dos pesquisadores, pois esta deve ser capaz de ser compreendida pelo entrevistado para conseguir extrair com clareza os dados almejados ${ }^{8}$. A técnica da entrevista é definida como uma interação social entre entrevistador e entrevistado através de perguntas e respostas na qual os dados serão obtidos $^{6}$. O roteiro de entrevista foi organizado em quatro blocos, quais sejam, (1) a vida do discente antes da faculdade, assim como a sua visão e experiência da enfermagem, (2) Autonomia profissional e a experiência no processo de formação profissional, (3) O pensamento social acerca da autonomia profissional e (4) O futuro da enfermagem e o futuro profissional.

No entanto, é necessário compreender importância da análise dos dados para o projeto, que tem o objetivo de organizar os dados de uma forma que torne possível seu entendimento e interpretação, visando obter a resposta para a problemática investigada ${ }^{6}$. Ao concordar com esta assertiva, destaca-se que a análise realizada foi a de conteúdo, que aflora como técnica que indica a percepção de uma realidade ostensível ou de uma realidade oculta, que não está explicita de forma nítida na fala, o que exige do pesquisador uma visão detalhada da pesquisa capaz de uma pré-compreensão do indivíduo e sua comunicação com o contexto ${ }^{8}$. Para isso, as metodologias como as perguntas utilizadas para a entrevista devem ser capazes de atingir de forma direta ou indireta o tema de interesse do estudo. 
No processo de realização da análise, definiu-se, como unidade mínima, a Unidade de Registro e esta foi definida como o menor trecho discursivo que contém qualquer relação ou referência ao objeto de estudo, caracterizando-se, como consequência, como análise temática. Em seguida ao realizar o ajuntamento das diferentes unidades de registro, chegou-se à construção das Unidades de Significação, gerando blocos teóricos que mostrem diferentes facetas do objeto de estudo ou, ainda, as dimensões representacionais que o compõem. Para a conformação das categorias que compuseram os resultados, foi utilizada a aglomeração das unidades de significação, atentando especialmente para aquelas que eram transversais ao maior número de sujeitos e que possuíam maior saliência (frequência e ocorrência) nos discursos analisados.

\section{RESULTADOS}

São apresentados os dados referentes às Unidades de Registro (URs), que foram obtidas pelas 20 entrevistas dos participantes selecionados para esta pesquisa. Ao agrupar estas URs foram criados os temas que, agrupados, definiram as categorias de análise. Este estudo teve um total de 776 (100\%) unidades de registro, distribuídas em 316 temáticas que estão presentes nas 5 categorias, a saber: $O$ estudante diante da enfermagem e da faculdade: escolhas e atitudes; a autonomia no processo ensino-aprendizagens: avanços e desafios; a complexidade da autonomia do enfermeiro: suas limitações e desafios; a autonomia no contexto das unidades de saúde: práticas profissionais e seus contextos; a complexidade da autonomia do enfermeiro: suas imagens e sua dimensão ideal. Cada categoria, discriminada na Tabela 1, é aprofundada a seguir.

\section{Tabela 1. Representações das categorias do estudo}

\begin{tabular}{|l|c|c|}
\hline Temas/unidades de significação & $\begin{array}{c}\text { Número de Unidades } \\
\text { de Registro }\end{array}$ & $\begin{array}{c}\text { \% de Unidades de } \\
\text { Registro por tema }\end{array}$ \\
\hline $\begin{array}{l}\text { O estudante diante da Enfermagem e da faculdade: } \\
\text { escolhas e atitudes }\end{array}$ & 112 & $15 \%$ \\
\hline $\begin{array}{l}\text { A autonomia no processo de ensino - aprendizagens: } \\
\text { avanços e desafios }\end{array}$ & 151 & $19 \%$ \\
\hline $\begin{array}{l}\text { A complexidade da autonomia do enfermeiro: } \\
\text { suas limitações e desafios }\end{array}$ & 162 & $21 \%$ \\
\hline $\begin{array}{l}\text { A autonomia no contexto das unidades de saúde: } \\
\text { práticas profissionais e seus contextos }\end{array}$ & 205 & $26 \%$ \\
\hline $\begin{array}{l}\text { A complexidade da autonomia do enfermeiro: } \\
\text { suas imagens e sua dimensão ideal }\end{array}$ & 146 & $19 \%$ \\
\hline Total & 776 & $100 \%$ \\
\hline
\end{tabular}

Fonte: os autores. 
$O$ estudante diante da enfermagem e da faculdade: escolhas e atitudes

Formada por 112 unidades de registro (URs) e 30 unidades de significação, que equivale a $15 \%$ dos dados analisados, esta categoria trata das escolhas e atitudes dos estudantes diante da enfermagem e da faculdade, motivo da escolha pela profissão e da graduação, entendimento sobre a profissão, experiências positivas, atitudes dos discentes perante a enfermagem, expectativas após a formação e outros aspectos relacionados à esta categoria. Os temas que mais se destacaram dentro da categoria foram: Estudar mais; Experiência positiva na unidade básica de saúde (UBS); Escolha da enfermagem por afinidade e quero trabalhar; dentre outros que poderiam ser citados.

Ao começar a analisar esta categoria, torna-se necessário abordar os fatores que levaram os acadêmicos, a partir das suas representações, a se inserirem no curso de graduação de enfermagem. Um dos motivos que se destacaram foi a influência familiar. Nota-se que, no discurso dos entrevistados, a primeira escolha pela graduação não foi enfermagem. A posteriori, a intervenção de familiares, contrários à sua primeira opção, acabou por determinar a sua inserção no curso de graduação de enfermagem. Torna-se importante destacar, também, que, ao mesmo tempo, observa-se uma aceitação familiar do curso de enfermagem como promissor e valorizado.

Outro fator que se destacou quanto à inserção dos estudantes na graduação, dentre os discursos, foi a afinidade por matérias do ensino fundamental, ou então a semelhança da personalidade do estudante com a dos enfermeiros. Ainda com relação à inserção dos participantes no ensino superior, outro fator relevante encontrado nesta pesquisa foi a escolha da profissão por já ter cursado o curso técnico na área. Os profissionais que já estão inseridos na enfermagem ou que tiveram contato com a profissão, em nível técnico ou auxiliar, tem a graduação de enfermagem como uma opção para realizar a ascensão social. Além disto, destaca-se a experiência na área e o desenvolvimento de afeto pela profissão, o que implica uma maior possibilidade de escolha.

Após a inserção na faculdade, destacam que a autonomia profissional não é do conhecimento dos próprios ingressantes, o que significa que, possivelmente, não o é também da grande população. Ou seja, foi a inserção específica no curso de enfermagem que fez com que este grupo pudesse identificá-la. Ressalta-se que é provável que estas descobertas permitidas pela graduação sejam as responsáveis pela mudança na empatia pela profissão. Alguns sujeitos argumentaram que gostam da profissão, algo que não existia antes.

Há um entrosamento entre o aluno e o curso, bem como o futuro profissional e a enfermagem, ao desenvolverem uma relação de afeto, o que termina com o fato da permanência no curso e o gostar da profissão escolhida e que será desenvolvida no futuro. Este gostar da área e de disciplinas específicas facilita o processo ensinoaprendizado, agrega melhor o conhecimento negociado e motiva os alunos a querer aprofundálo, assim como ampliar a possibilidade destes em buscar ser um profissional de destaque, bem inserido dentro do mercado de trabalho. 
Ao entrarmos neste tema, em relação ao estudo, os entrevistados afirmaram que há necessidade de sempre buscar o conhecimento técnico e científico e que este, embora faça parte da graduação, não se limita a ela, a fim de aprimorar suas atividades como profissional, com o objetivo de alcançar a plenitude no domínio da profissão. Com o domínio deste conhecimento, almejam poder se posicionar como um profissional capacitado, capaz de exercer sua função com segurança e autonomia. Quando consideram as atividades após o término da graduação, uma quantidade expressiva de sujeitos retornou ao tema do estudo afirmando o desejo de estar em constante busca de conhecimento, o que torna evidente a preocupação quanto à estagnação de conhecimento acerca da profissão. É possível destacar a importância dada por estes em estar sempre acompanhando as evoluções que circundam a profissão e reconhecem, através destas, as constantes descobertas científicas da área e sua grandiosidade.

Outra temática que se destacou nesta categoria, também com o pensamento no período pósuniversitário, foi a atitude dos acadêmicos de se inserirem rapidamente no mercado de trabalho. Os entrevistados estão almejando bons empregos dentro da área, com o intuito de conseguir viver bem com seu salário e suprir as atividades que tem, como o lazer. No conjunto das representações dos depoentes, o salário advindo da enfermagem dá, apenas, para se manter ou suprir as necessidades. Outros manifestaram o desejo de retornar à universidade como professores, a fim de contribuir com a formação de novos profissionais, na perspectiva de querer gerar a mudança. Neste sentido, desejam o retorno como professor a partir da vontade de transmitir seu conhecimento de forma a participar junto aos demais docentes neste processo de constante transformação da profissão.

Ao levar em consideração a transformação supracitada, uma parcela significativa afirmou querer ser um profissional capaz de fazer a diferença no seu cenário de trabalho. Desejam atuar com autonomia e poder realizar suas tarefas de uma forma transformadora, fazendo a diferença no cenário atual da enfermagem.

\section{A autonomia no processo ensino- aprendizagens: avanços e desafios}

Nesta categoria, formada por 151 URs e 38 unidades de significação, equivalente a 19\% dos dados analisados, são encontrados os avanços e desafios enfrentados pelo processo ensinoaprendizado acerca da autonomia profissional do enfermeiro, as dificuldades e facilidades dos acadêmicos para desenvolverem sua autonomia, a diferença entre a teoria e a prática, como estes qualificam sua formação e a relação dos docentes e discentes neste processo. Entre os temas que mais se destacaram dentro da categoria estão: Visão acerca da diferença entre teoria e prática; autonomia foi ensinada na matéria de gerência; formação boa, mas incompleta; prática defasada e praticar, facilitam aprender.

Um dos aspectos importantes foi que, quando indagados sobre a autonomia profissional ser estudada na graduação, a maioria dos entrevistados disse haver estudado a temática na disciplina de gerenciamento de serviços de saúde e processos de trabalho na enfermagem, que atualmente fazem parte das disciplinas do oitavo período da graduação na universidade que o 
estudo foi realizado, sendo um avanço no ensino de enfermagem. Esta proporciona uma visão clara dos acadêmicos e a compreensão destes sobre a autonomia presente em sua profissão, contudo esta é apenas uma das disciplinas presente no curso de graduação de enfermagem.

Outro fator importante realçado diz respeito às disciplinas serem fragmentadas, abordando apenas os conteúdos pertencentes a elas e ignorando o contexto da profissão e da prática de cuidado como um todo, assim como as suas complexidades. Este discurso é uma preocupação dos sujeitos na visão de seu ambiente de trabalho de uma forma ampla, que é limitada por atitudes de docentes que, continuamente, voltam a visão daqueles para os limites da disciplina, fragmentando o ensino e o cuidado.

Torna-se importante destacar que os sujeitos apontam o processo de formação como aquele que não permite a construção da liberdade e do papel do enfermeiro em sua amplitude própria e natural, delimitando ações pontuais de procedimentos de enfermagem e não o exercício do cuidado de enfermagem em sua profundidade e em sua abrangência. Ao questionar sobre a relação teoria-prática, os acadêmicos apontam a sua existência de forma muito expressiva e visto de maneira negativa para o ensino. Afirmaram haver esta diferença e que esta consiste em um aprendizado teórico que diverge, na maioria das vezes, com o que é visto no campo prático. A diferença entre a teoria e a prática é resultado de diversos fatores que divergem: a dificuldade da disponibilidade de recursos nas práticas é uma delas, impedindo que os procedimentos presentes em livros ou artigos sejam realizados da maneira descrita. É bom observar também que embora haja diferença entre a bibliografia e o ensino transferido é um grande desafio enfrentado pelas graduações da área da saúde e, principalmente, a enfermagem.

Ainda no tocante ao campo prático, há um destaque em sua representação, apreendendo-o como um dos facilitadores para assimilar e fixar o que se passa na teoria, porém este mesmo campo prático se constitui como um dos principais desafios presentes na graduação, pois outro tema de destaque foi a defasagem da parte prática da graduação. A parte prática é um desafio para a graduação, segundo os entrevistados. $\mathrm{Na}$ universidade em tela, a prática se dá em um cenário público municipal, com déficit pessoal e material para os profissionais exercerem seu trabalho. Este pode ser um dos possíveis fatos que levaram os discentes a ter esta visão da prática, contexto que terminará por encontrar, caso se depare com uma oportunidade de emprego na rede pública.

Ainda na parte prática, os entrevistados afirmaram que há interferência dos professores quanto a eles exercerem a prática das atividades, especialmente no que concerne ao fazer, praticar ou debater destes estudantes inseridos no campo prático, impedindo ou limitando estas tarefas e atitudes de forma livre e autônoma. Isso pode acontecer pelo fato dos professores não confiarem neles ou no conhecimento que disponibilizaram para os alunos. Outro fator é a preocupação com a perda do campo prático, o que leva a perceber a escassez deste para a universidade. Percebese mesmo que estes passem todo conteúdo para uma prática eficaz dos seus acadêmicos, ainda o vêem como não confiáveis na prática. 
Outro desafio foi a forma de alguns professores ensinar, que dificultava o processo ensino aprendizado, ao proporcionar um conteúdo de uma maneira não atrativa para os estudantes, sem interação, muito preso aos slides e aulas muito extensas. Visto de uma maneira pouco diferente por outros entrevistados. Embora tenham sido destacadas algumas dificuldades até o momento, existem grandes avanços presentes no desenvolvimento de pesquisas, onde uma quantidade significativa de entrevistados afirmou ter passado por experiências positivas, o que mostra o quão expressivo são as pesquisas de enfermagem, e sua importância para os estudantes. Estas experiências positivas mostram o desvendar de um novo universo explorado com êxito por eles, a participação desta nova geração de enfermeiros cada vez mais na pesquisa.

Ao mesmo tempo, os professores também foram elogiados pelos entrevistados por estarem sempre a ensinar a valorizar a profissão e por mostrarem como o enfermeiro atua com competência. Neste sentido, o importante era conseguir passar o valor e a competência da profissão. Para finalizar esta categoria não se pode deixar de analisar a qualificação da graduação a partir dos entrevistados, muitos destes veem sua formação como boa, porém ainda há dificuldades a serem sanadas e desafios a serem cumpridos, para que ela alcance outro patamar.

\section{A complexidade da autonomia do enfermeiro: suas limitações e desafios}

Esta categoria é formada por 162 URs e 33 unidades de significação, equivalente a $21 \%$ dos dados analisados. Versa sobre a complexidade da autonomia do enfermeiro em suas limitações e desafios. Nesta será abordada a diferença da autonomia nos diferentes ambientes assistenciais, tais como nos hospitais e nas unidades básicas de saúde, o desafio do conhecimento perante a autonomia, as limitações dos entrevistados sobre o assunto, a relação entre profissionais de saúde e a relação entre autonomia e autoridade. Entre os temas que mais se destacaram dentro da categoria estão: Enfermagem subordinada à medicina; Vê muita diferença entre autonomia profissional no hospital e na Unidade Básica de Saúde (UBS); Poucos profissionais tem autonomia na prática; Falta de conhecimento e dificulta autonomia; Não tem autonomia por medo; Não há relação entre autonomia profissional e autoridade; A enfermagem deixa a desejar; Individualidade como ponto negativo.

Para começar a discutir sobre as limitações e os desafios, muitos dos entrevistados, quando indagados quanto ao conhecimento que possuíam acerca do campo de atuação do enfermeiro antes do ingresso na graduação, afirmaram que se resumia apenas à área hospitalar. É nítido que se viram diante da limitação de seus pensamentos quanto à profissão estar ligada apenas à área hospitalar, mesmo esta sendo tão ampla e de extrema importância no processo saúde-doença. Uma das maiores dificuldades para o enfermeiro obter autonomia, segundo os participantes, é a desvalorização da profissão, que se apresenta como um dos fatores determinantes para que este atue sem autonomia. Na questão do envolvimento do profissional e seu empenho enquanto enfermeiro no cotidiano de sua prática, muitos entrevistados revelaram que alguns deixam a desejar na assistência, inclusive apresentando desinteresse com a assistência. Uma possibilidade de compreensão deste fenômeno, 
também para os participantes, é a desvalorização que os desmotivam, o que tende a se agravar com o aumento do tempo de serviço.

Outro ponto negativo relatado foi o individualismo presente na sala de aula, dificultando o exercício de relações com outras pessoas e profissionais. Para os discentes, este individualismo é um grande desafio para obter autonomia profissional, visto que a coletividade da profissão passa a ser representada como de extrema fragilidade. Este fato apresenta-se como curioso, pois, se por um lado, a enfermagem é uma profissão que necessariamente é uma equipe, por outro, os sujeitos desta pesquisa confirmam o desenvolvimento do cuidado de enfermagem com práticas fragmentadas entre os diferentes atores sociais, sem união nem mesmo nas questões mais corporativas da profissão em uma instituição ou instância governamental.

Outra limitação é a representação social de subordinação da enfermagem à medicina e a presença de enfermeiros nos campos práticos trabalhados pelos participantes. Alguns dos elementos que conformaram esta construção simbólica por parte dos entrevistados foi a necessidade ou a importância da confiança do médico para sua atuação e a subordinação das equipes de enfermagem e suas atividades, por livre iniciativa, ao médico. Neste contexto, a autonomia, em si, é vista em poucos profissionais pelos discentes em suas atuações práticas. Dentro da realidade das práticas assistenciais, se depararam com enfermeiros apreendidos como autônomos, pois não generalizaram suas falas. Estes enfermeiros, por sua vez, são minoria perto do quantitativo de profissionais conhecidos dentro de suas práticas e experiências.
Entre os motivos explicativos para a pouca autonomia dos profissionais, destacam-se o medo como um dos fatores que assombram os enfermeiros, medo este que está presente de diversas formas, segundo os discentes. Um destes medos chama bastante a atenção, o desconhecimento. Tendo em vista que o erro é uma falha humana, este pode ser minimizado a partir do conhecimento. Quanto a esta possibilidade, tendo o conhecimento e confiança, o medo de errar ao exercer a profissão ou causar algum dano vital é consideravelmente minimizado, embora seja sempre uma possibilidade. Além do desconhecimento, o desinteresse pelo estudo é outro desafio a ser enfrentado para a superação do medo, gerando pouca autonomia na prática profissional, segundo os estudantes. Pesquisar e desenvolver um conhecimento crítico reflexivo é segundo eles, fundamental para se ter autonomia em sua atuação.

Para outros entrevistados, a autonomia profissional é dependente de diversos fatores e profissionais. Um deles é a dependência do local onde este profissional se encontra e de quem ele é. Referem-se a dois processos básicos: primeiro a dependência, no entanto, a dependência aqui não está necessariamente atrelada à medicina, mas parece se relacionar à compreensão de que a enfermagem se encontra em uma área de interface entre várias profissões, o que acarreta uma certa dificuldade na compreensão do essencial e da importância da profissão.

A segunda questão é que a autonomia não está na dependência da própria profissão ou de sua construção teórica, legal e prática, mas na dependência de fatores internos e externos à enfermagem. No que tange aos internos, 
destacam-se as características pessoais do próprio enfermeiro e da equipe de enfermagem e do modo como o enfermeiro se estabelece e se coloca no seio da equipe de saúde. Quanto à externa, esta se relaciona à estrutura e à visão de trabalho de uma localidade em específico, de uma instituição determinada e das características dos profissionais que compõem a equipe de saúde.

Ao serem indagados quanto à autonomia na UBS e no hospital, os entrevistados responderam de forma expressiva que há diferença entre as duas áreas de atuação, positivamente na unidade básica e de forma negativa nos hospitais. Ao mencionarem o lado positivo nas UBS, leva-se a considerar a possível afeição destes por este tipo de assistência que os remete à positividade.

\section{A autonomia no contexto das unidades de saúde: práticas profissionais e seus contextos}

Estacategoriaé formadapor205URse41 unidades de significação, equivalente a $26 \%$ dos dados analisados. Traz o conteúdo sobre a autonomia existente nas práticas profissionais e os seus contextos, a realidade da autonomia na prática, a autonomia do enfermeiro na UBS, a relação entre autonomia profissional e conhecimento, relação do enfermeiro com os demais profissionais da equipe de saúde, atividades privativas do enfermeiro e os conceitos sobre o enfermeiro. Entre os temas que mais se destacaram dentro da categoria estão: Autonomia do enfermeiro na UBS; enfermeiro faz cuidados diretos ao paciente; autonomia na prática; relação do enfermeiro com os outros profissionais da equipe de saúde; conhecimento facilita autonomia; relação autonomia profissional conhecimento; autoridade é ter postura de chefe; Enfermeiro é gerente do posto; autonomia e respeito da equipe; passagem de sondas nasogástricas é exclusiva do enfermeiro; e profissão voltada para o cuidado.

Quanto à autonomia na prática, alguns dos entrevistados afirmaram que não é um fenômeno tão frequente como se desejaria, não sendo presenciada por todos. No entanto, o pouco que se vê é satisfatório. Portanto há o reconhecimento da presença da autonomia profissional do enfermeiro, mesmo não sendo praticada por todos os profissionais, o que, consequentemente, dificulta a percepção do aluno acerca dela. De um modo geral, quando percebem a presença da autonomia, geralmente está ligada ao profissional inserido na UBS, onde conseguem ver este gerenciar uma unidade, a consulta de enfermagem e o comportamento dele frente às mais diversas situações que exige conhecimento.

A autonomia observada e vivenciada na UBS pelos discentes apresenta-se ligada à liberdade do enfermeiro de executar determinadas ações e ser gestor do ambiente e que a autonomia dos profissionais se apresenta como um fato na medida em que os profissionais podem executar determinadas tarefas, como prescrição de medicamentos, coletas de preventivo e consulta de enfermagem com maior liberdade, bem como estar na posição de gestão da unidade básica.

Ao mesmo tempo, chama a atenção de que a representação da autonomia, para os discentes, possui relação com a atividade de gestão e de gerência da unidade. Quando o enfermeiro assume um cargo de grande responsabilidade, ele é visto como alguém detentor desta autonomia. O que ficou evidente neste trabalho é que os estudantes de uma forma marcante alegaram a 
necessidade do conhecimento para ter autonomia, conhecimento científico e teórico, para te embasar e dar segurança à sua prática profissional, bem como garantir sua liberdade e autonomia para atuar efetivamente como enfermeiro.

Quando abordada a questão relacionada à autonomia no trabalho em equipe, os acadêmicos informaram que a autonomia é maior dentro da equipe. Ao mesmo tempo, destacaram que, quanto maior a autonomia, maior é o respeito destes com o enfermeiro. Identificou-se que há uma hierarquia dentro da equipe de enfermagem e que esta equipe se apresenta sensível à realidade da autonomia que enfermeiro possua ou não. Simultaneamente, os dados parecem indicar que a equipe de saúde é também sensível à esta questão, comportando-se com coerência com a presença de maior ou menor autonomia por parte do enfermeiro, o que termina por gerar maior ou menor respeito à atuação, à decisão e à palavra do profissional enfermeiro.

Dentre os entrevistados, a principal ação ou procedimento exclusivo do enfermeiro reconhecido por alguns, é a consulta de enfermagem. Além da consulta de enfermagem que se caracteriza por ser uma tecnologia de trabalho muito presente na rede básica da assistência, destacam-se outras atividades mais características do ambiente hospitalar, como sendo próprias do enfermeiro. Estas são atividades exclusivas do enfermeiro dentro da própria equipe de enfermagem no contexto hospitalar, considerando-se, então, que a ideia central neste contexto é que os procedimentos invasivos aos corpos dos pacientes são de exclusividade daquele profissional, mesmo reconhecendo-se que, em determinadas situações, outros profissionais de nível superior também o possam realizar. A concepção de que os procedimentos invasivos são prerrogativas do enfermeiro apresenta-se com coerência com a Lei do Exercício profissional que advoga justamente esta ideia.

Quanto à enfermagem, os entrevistados guardam um conceito que o enfermeiro é uma profissão voltada para o cuidado. É possível compreender que os estudantes que fizeram tais afirmações limitaram o cuidado prestado pela enfermagem ao indivíduo, tratando dele de maneira mais precisa, ou focada nele de uma maneira indireta, sem mencionar o cuidado coletivo e familiar, que também faz parte do contexto das práticas da profissão.

Para os discentes, a autoridade é se posicionar como chefe, sendo rude, autoritário e sem ouvir as opiniões dos outros profissionais. A palavra autoridade para estes remete a algo ditatorial, quando na realidade este pensamento trata-se da liderança denominada autocrática, que, em determinadas situações, é bem-vinda à prática de liderança. O enfermeiro, como líder da sua equipe, terá que saber lidar com os diferentes tipos de liderados e liderança, transitando entre eles.

Nesta categoria foi possível discutir sobre as práticas profissionais e o contexto em que estas estão inseridas, como se encontra a autonomia na prática pelo ponto de vista destes estudantes, sua evolução nas Unidades Básica de Saúdes, assim como as relações entre o enfermeiro e os outros profissionais da saúde interferem na sua forma de trabalho. O conhecimento é visto de forma positiva como um facilitador 
para os profissionais obterem a autonomia em suas ações. Porém, vimos que mesmo os profissionais recém-formados têm dificuldades, o que torna evidente a constante construção do conhecimento e, como consequência, a formação da autonomia. Foi apresentada, também, a capacidade de eles reconhecerem a enfermagem como um processo de cuidado amplo de modo mais individual do que coletivo, nos diferentes tipos de assistências. A complexidade da relação da liderança com autoridade também foi exposta, sendo o enfermeiro responsável pelas atitudes de sua equipe, respondendo junto a eles.

\section{A complexidade da autonomia do enfermeiro: suas imagens e sua dimensão ideal.}

Nesta última categoria, formada por 146 URs e 32 unidades de significação, equivale a 19\% dos dados analisados. Em seu contexto estão presentes as complexidades da autonomia do enfermeiro, suas imagens e sua dimensão ideal, as mudanças geradas pela faculdade no pensamento destes discentes acerca da enfermagem e a autonomia. Entre os temas que mais se destacaram dentro da categoria estão: Pensamento quanto à enfermagem modificou; para ter autonomia tem que ter conhecimento; conhece ações e procedimentos exclusivos do enfermeiro; conhecimento quanto às áreas de atuação do enfermeiro; autonomia é colocar em prática tudo que estudei; autonomia é realizar suas ações com segurança; autonomia é saber o que estou fazendo; há relação entre autonomia e autoridade.

Dentre os entrevistados, uma grande parcela afirma a inserção na graduação de enfermagem ter modificado seu pensamento quanto à profissão.
Muitos dos discentes entrevistados trouxeram, em suas falas, uma dimensão afetiva, pensando no cuidado humanizado. A dedicação ao seu trabalho, além da dimensão afetiva presente, imbui a preocupação quanto ao atendimento e ao cuidado de qualidade que deve ser prestado pelo profissional ao próximo, cuidando dele de forma humanizada e livre de estigmas.

Ao serem indagados se em algum momento já ouviram falar destas ações e procedimentos exclusivos na graduação, uma parcela significante afirmou positivamente. Nas afirmações positivas destes e dos demais acadêmicos, demonstra que a graduação disponibiliza esta informação. No entanto, os sujeitos apontam que há uma predisposição individual na busca pela fixação deste conhecimento de modo a garantir a sua autonomia.

No tocante à autonomia, muito dos entrevistados afirmaram que a autonomia em si é colocar em prática o que foi aprendido enquanto acadêmico levando em conta sua legislação e seu conhecimento. Para outros entrevistados não muito distantes desta realidade, afirmam que é ele realizar atividades da sua profissão, assim, ter autonomia profissional é ser capaz de realizar as atividades de sua competência sem interferência de outrem. Desta forma este enfermeiro é livre para desenvolver suas ações, seus procedimentos e liderar sua equipe. Outros estudantes, concluíram que a autonomia é saber o que ele está fazendo, chegando ao desfecho que, para se ter autonomia, os profissionais têm que saber o que vão fazer para que na hora que necessite agir, eles possam fazê-lo de maneira natural e sem interferência interna ou externa. 


\section{DISCUSSÃO}

Ressalta-se que este estudo apresenta limitações, uma vez que fora realizado apenas em instituição federal de ensino, logo, não foram investigadas universidades estaduais ou instituições de ensino privado onde os alunos, por sua vez, podem ter uma representação social da autonomia do enfermeiro diferente dos resultados do presente estudo. Outra limitação refere-se ao número de pessoas investigadas, sendo alcançado o número mínimo sugerido para estudos desta natureza.

De acordo com os achados deste trabalho, quanto a inserção no curso de graduação de enfermagem, outros estudos demonstram que os ingressantes desconheciam o curso no momento de sua inserção e, tiveram, como motivação para tal escolha, a afinidade com a área'. Em outro estudo, percebe-se que os entrevistados optaram pelo curso de graduação de enfermagem por sua proximidade às outras profissões da área da saúde ${ }^{10}$.

Outros autores, ao realizarem suas pesquisas com acadêmicos de enfermagem encontraram, como afinidade destes, as disciplinas como semiologia e farmacologia, sendo observada a preferência e a valorização das disciplinas de cunho prático. Percebe-se, então, a importância desta disciplina na grade curricular ${ }^{11}$. Outro autor relata que a maioria dos egressos consegue se inserir no mercado como enfermeiro ${ }^{12}$. Neste mesmo estudo é visto que grande parte destes concluintes continua a trilhar em busca de agregar conhecimento através da realização de cursos de pós-graduação lato sensu (especialização) e uma minoria através da pós-graduação stricto sensu (mestrado e doutorado). Uma metodologia utilizada denominada de Aprendizagem Baseada em Problemas (APB), tem como finalidade problematizar casos reais para exemplificar os conteúdos trabalhados, bem como desenvolver a autonomia do discente frente a seu processo de formação ${ }^{13}$.

No que tange ao processo de formação, destacase que, desde a década de 90 , diferentes autores ${ }^{14}$, apontam o processo de docilização dos estudantes neste contexto, em que a norma e a regra tendem a ter um peso maior do que a criatividade e a liberdade. Simultaneamente, a interlocução do docente com o discente sobre o cuidado prestado nem sempre ocorre no dia a dia das atividades práticas. Isto se dá devido à avaliação de que o discente já adquiriu estas habilidade e autonomia, o que dispensa essa comunicação pré e pós-procedimento. No entanto, durante suas observações, os docentes não exploraram a reflexão destes sobre a ação, implicando em prejuízo, principalmente aos estudantes que poderiam ter refletido sobre diferentes facetas do cuidar ${ }^{15}$.

Dentro de outra pesquisa ${ }^{15}$, há a observação e a análise quanto à atividade teórico-prática, identificando que apenas em alguns momentos o ensino, que é moldado na demonstração e imitação, conseguiu estimular o pensamento crítico reflexivo dos estudantes quanto à sua ação. E ainda afirma que é dever dos docentes estimulá-los à reflexão sobre o cuidado prestado quanto ao processo de ensino empregado por este docente.

Destaca-seque odesenvolvimento das habilidades do pensamento crítico, pode proporcionar um enfermeiro mais crítico e autônomo em sua atuação ${ }^{16}$. Contudo, outro autor ${ }^{19}$, acredita que 
o desenvolvimento destas habilidades deve começar na graduação onde o enfermeiro pode e deve desenvolver atitudes críticas, criativas e transformadoras. Para isto, é indispensável estratégias que valorizem e desenvolvem estas habilidades, de modo a expandir o intelecto e o saber da profissão.

A graduação tem o dever de capacitar os estudantes para transformarem sua cognição e trabalho, a fim de encararem as novas demandas da sociedade, tendo em vista o processo de aprender a adquirir conhecimento, realizar suas atribuições, ser profissional e se ver inserido como tal. Para isto, é necessária a utilização de tecnologias problematizadoras possibilitando a transformação de suas realidades, implantando-a na sociedade. É importante o acordo entre as atividades acadêmicas e a realidade de trabalho e para isso é necessário subjugar a formação mecanicista e utopista que desconsideram a complicada realidade vivenciada na saúde ${ }^{17}$.

A autonomia e seu espaço no contexto da enfermagem está relacionada, na maioria das vezes, às características dos profissionais e ao contexto pessoal e institucional ${ }^{17-18}$. Quanto aos aspectos do trabalho realizado, como a consulta de enfermagem, esta não se encontra consolidada na instituição pesquisada. Este espaço não depende apenas do comportamento profissional, mas também se encontra ligada as ações inovadoras nos serviços de saúde, sejam privados ou públicos $^{18}$.

Quanto ao trabalho em equipe, a eficiência e a efetividade dos serviços de saúde necessitam da interação entre os profissionais e suas ações. Portanto, no contexto da equipe multiprofissional é necessária a comunicação efetiva entre os profissionais com processo de trabalho distintos, promovendo ligações e intervenções de cada área profissional. Este propõe, ainda, que para haver esta comunhão e interação multiprofissional no ambiente acadêmico é necessário que cada protagonista esteja interessado em demonstrar o interesse para que ocorra tal integração e comunhão dos saberes, com a finalidade de reinventar conceitos, desconstruir estigmas e construir uma atenção à saúde de forma compartilhada a partir da graduação ${ }^{19}$.

Os acadêmicos por sua vez demonstram haver diferença entre a autonomia profissional do enfermeiro na Unidade Básica de Saúde e hospital. Isto se dá pelo fato da sua autonomia profissional consistir em um espaço que podem atuar e buscar satisfação pessoal e dos clientes, refletindo positivamente em suas ações profissionais, sendo este capaz de autogovernar-se ${ }^{20}$. Outros estudos, apontam a delicada questão da autonomia do enfermeiro na rede básica, especialmente por alguns profissionais considerarem que a autonomia é simplesmente maior espaço de atuação, mesmo em se tratando de atividades delegadas, como a prescrição medicamentosa ${ }^{21}$.

A associação entre conhecimento em suas diferentes modalidades e a autonomia, sempre foi algo presente em diferentes autores ${ }^{21,22}$, uma vez que o exercício de uma prática autônoma da enfermagem relaciona-se necessariamente à construção de uma identidade profissional que expresse a especificidade da enfermagem na sociedade, o que significa a existência de um corpus de conhecimento específico da profissão. Ao discutir o papel próprio da profissão e as atividades privativas do enfermeiro, afirmaram 
que há uma dificuldade destes profissionais em responderem, com precisão, a esta questão, o que também aconteceu com alguns sujeitos desta pesquisa $^{21,22}$. Segundo os autores citados, houve profissionais que desconheciam a existência destas atividades ${ }^{23}$. Em outra pesquisa $^{24}$, os estudantes e os profissionais que concentrarem mais conhecimentos estarão em uma condição vantajosa para executar a sua autonomia. A exposição destes às ideias e conceitos de disciplinas, como a antropologia, a sociologia e a filosofia, maior será sua absorção de conhecimento, e sua pratica autônoma. Esta busca constante por conhecimento é importante para que ocorra o desenvolvimento de atitudes, habilidades e competências fundamentais à melhoria da organização do processo de trabalho do enfermeiro contribuindo, desta forma, para a resolutividade das ações em saúde ${ }^{25}$.

Através da análise dos dados, deve-se pensar que a formação acadêmica do enfermeiro deve proporcionar, a estes, uma visão crítica e reflexiva capaz de aguçar seu questionamento perante suas ações, de maneira transformadora e livre. Afirmam, ainda, quanto à necessidade da interação professor-aluno, pois seus reflexos influenciam no processo do conhecimento. $\mathrm{O}$ autor supracitado ainda menciona que a metodologia utilizada por professores no ensino do gerenciamento de enfermagem tem a preocupação de implementa-las de maneira estimulante, refletir sobre a realidade e aprender buscar conhecimento e evoluir ${ }^{11}$.

Neste contexto, foi encontrado que o enfermeiro gerente tem uma força histórica de trabalho na enfermagem, responsável por ser destacar de maneira técnica e social. Sendo possibilidades de benefícios agregados ao assumir um espaço de poder em relação à sua posição hierárquica ou partição do gerenciamento e ação, esta atividade privativa do enfermeiro é capaz de reforçar a autonomia da categoria entrelaçada à sua responsabilidade legal sobre a equipe ${ }^{26}$.

Ao discutir sobre a afetividade na enfermagem, não é incomum, entre os enfermeiros, baseado na ética e filosofia da profissão, a realização de formas de cuidados eficientes pautados no amor e no aspecto humano, com a finalidade de superar as dificuldades impostas por fatores sociais, institucionais ou econômicos ${ }^{27}$. Outro autor relata que quando o enfermeiro atua com amor, faz com que este produza um conhecimento capaz de limitar ou diminuir a dependência do paciente em relação ao profissional, através de aparatos técnicos e tecnológicos, bem como pela sabedoria humana, em que se procura intervir o mínimo possível e considerar o indivíduo como único e singular ${ }^{28}$.

Com relação à presença da pesquisa no cotidiano de alunos e profissionais de enfermagem, como apontado nos resultados, destaca-se que resultado semelhante foi achado em outro trabalho ${ }^{29}$, onde foi possível compreender que a educação e a pesquisa estão cada vez mais presentes no cotidiano do enfermeiro. Percebeuse, também, que a pesquisa, o conhecimento e a troca de informações tem sua importância nos diversos níveis de atenção à saúde e para todos profissionais membros da equipe de enfermagem e multiprofissional. Estes também afirmam que a educação permanente conduz o profissional à reflexão de suas ações, sendo responsável pelo enriquecimento profissional e pessoal, assim como valorizando a profissão e o profissional ${ }^{28}$. 


\section{CONCLUSÕES}

Conclui-se destacando que, deve-se começar o processo de autonomia profissional a partir do processo de formação, responsável pela construção do conhecimento científico e teórico imprescindíveis para este processo. Os discentes não alcançaram a plenitude destes fundamentos, tendo fatores de déficit, o ensino teórico-prático, as dificuldades com recurso pessoal, material e o relacionamento professor-aluno. Este contexto interfere em sua autonomia profissional e nas representações que estes grupos constroem sobre a própria autonomia.

É importante destacar a existência de uma representação social da autonomia profissional nestes estudantes, porém em fase de consolidação. Esta se depara com uma dimensão real, extraída da percepção dos estudantes diante da realidade vivenciada nas instituições de saúde e onde exerceram suas práticas como enfermeiros ou transitaram durante seu processo de formação, destacando as experiências positivas em estágio supervisionado. Neste cenário houve aproximação das dimensões idealizadas pelos discentes, ideais estes, presentes na relação do conhecimento como base para a obtenção da autonomia e identificação da autonomia presente no enfermeiro na Unidade Básica de Saúde.

A representação presente nestes acadêmicos quanto à autonomia profissional se dá na gerência, através de uma visão do poder, hierarquia, e visão privilegiada da sociedade. As representações da autonomia profissional do enfermeiro se voltam para o desempenho das atividades incluídas nos programas de saúde e procedimentos invasivos como a passagem de sondas, a coleta de preventivos e a consulta de enfermagem como instrumentos detentor e formador de tal autonomia.

A representação do cuidado, no entanto, se dá voltada para uma relação interpessoal e individual, com o cuidado prestado direto ao paciente enfermo. A visão do cuidado correspondente ao próximo na sua singularidade, porém humanizado. Desta maneira, deixa-se de enxergar a pluralidade e sua dimensão coletiva, levando a significar que a representação da autonomia no âmbito do cuidado se faz presente na liberdade de atividades praticadas junto a um paciente e não na atenção à coletividade e à família.

Há também presente entre os participantes uma complexidade da representação social da autonomia na qual o enfermeiro encontra-se como detentor e absorvente das atividades centrais da equipe de saúde, pondo-se como o intercâmbio entre os diversos serviços de saúde e informações no seu contexto de trabalho. Esta complexidade termina por fazê-lo como imperceptível, na maioria das vezes, para a instituição, a sociedade e a própria profissão, ao mesmo tempo que o põe no centro das ações e decisões, o que significa a existência de um poder considerável por parte destes profissionais.

Notou-se a preocupação dos acadêmicos quanto à necessidade da busca constante por conhecimento, visto que, por uma ótica crítica, mesmo com a impossibilidade da detenção de todo conhecimento pleno presente na profissão, está presente nas entrelinhas de seus discursos, a insegurança e o despreparo para a sua inserção autônoma no mercado de trabalho. O 
conhecimento mencionado pelos discentes de uma forma abundante e assertiva relacionada à obtenção da autonomia profissional, demonstra a importância deste para o cotidiano profissional, pois o conhecimento teórico e científico amplia e molda a forma cognitiva do enfermeiro, capaz de qualificar este para exercer sua função de maneira livre e responsável.

Apesar de ter atingido o objetivo previamente elencado, este estudo apresenta algumas fragilidades que impedem a extensão de seus resultados, como o fato da entrevista ter sido realizada apenas em uma única turma no último período presente no cenário do estudo e o número amostral ser reduzido, apenas, a 20 entrevistados. No entanto, este traz uma ampla importância da abordagem quanto à autonomia profissional na formação do enfermeiro, a fim de favorecer a profissão formando profissionais capazes de exercer suas atividades de forma consciente e autônoma baseada no conhecimento científico continuo capaz de modificar o pensamento social quanto ao profissional enfermeiro.

Cabe destacar que há escassez de estudos semelhantes de impacto para analisar a representação social da autonomia profissional para estudantes de enfermagem de instituições federais, principalmente em contexto de interiorização. No contexto acadêmico, tanto quanto o assistencial, há inovações constantes com relação às novas metodologias de aprendizado, portanto há necessidade de se pesquisar quando a sua eficácia, assim como aprofundar estudos como estes para estimular a formação de novos enfermeiros com plena autonomia. Diante disso, sugere-se a ampliação do estudo, investigando um maior número de participantes bem como envolvendo acadêmicos de instituições estaduais e privadas.
Agradecimentos: Érick Igor dos Santos (in memorian) pela orientação zelosa e competente do estudo original que possibilitou a construção desta produção.

Conflito de interesses: Os autores declaram que não houve conflitos de interesse.

\section{REFERÊNCIAS}

1. Silveira CA, Paiva SMA. A Evolução Do Ensino De Enfermagem No Brasil: Uma Revisão Histórica. Cienc Cuid Saude. 2011; 10(1): 1-9.

http://dx.doi.org/10.4025/cienccuidsaude.v10i1.6967

2. Santos WN. Sistematização da assistência de enfermagem: o contexto histórico, o processo e obstáculos da implantação. J Manag Prim Health Care. 2014; 5(2):1538.

3. Supametaporn P. The Conceptualization of Professional Nurse Autonomy. J Nurs Sci. 2013; 31(1): 1-6.

4. Fentanes LRC, Hermann AP, Chamma RC, Lacerda MR. Autonomia profissional do Enfermeiro: Revisão Integrativa. Cogitare Enferm. 2011; 16(3): 530-5.

5. Jodelet D. Social representations study and interlocution between knowledges in a globalized space. Jakarta, University of Indonesia. In Permanadeli R, Jodelet D, Sugiman T, editors. Production of Knowledge and Social Representations. Jakarta, University of Indonesia, 2012. p: 1-17.

6. Gil AC. Como elaborar projetos de pesquisa. 6. ed. São Paulo: Atlas; 2017.

7. Jodelet D. A representação: noção transversal, ferramenta da transdisciplinaridade. Cadernos de Pesquisa. 2016; 46(162): 1258-71. https://doi.org/10.1590/198053143845

8. Cavalcante RB, Calix, TOP, Pinheiro, MMK. Análise de Conteúdo: considerações gerais, relações com a pergunta de pesquisa, possibilidades e limitações do método. Inf. \& Soc.:Est. 2014; 24(1):13-8.

9. Câmara AG, Germano RM, Valença CN, Malveira FAZ, Pinto DPSR, Cossi MS. Motivations of students to study for nursing: between empathy and the job market. Rev enferm UFPE. 2014; 8 (2): 346-50.

10. Balem JGT, Lunardi VL, Bordigon SS, Barlem ELD, Lunardi Filho WD, Silveira RS, Zacarias CC. Opção e evasão de um curso de graduação em enfermagem: percepção de estudantes evadidos. Rev Gaúcha Enferm. 2012; 33(2): 1-9.

11. Andrade LDF, Porto SCAS, Lima ÉAR, Santos NCCB, Pinto MB, Medeiros HA. Abordagens pedagógicas na formação do enfermeiro gestor: concepção de discentes ingressantes. Revista da Universidade Vale do Rio Verde. 2016; 14(1): 323-32. https://doi.org/10.5892/ruvrd.v14i1.2476 
12. Lima A, Lopes LCS, Soane AMNC, Fortes AFA. Egressos de enfermagem: potencialidades no processo de formação profissional para inserção no mercado de trabalho. Indagatio Didactica. 2017; 9 (4): 65-80.

13. Campos LRG, Ribeiro MMR, Depes VBS. Autonomia do graduando em enfermagem na (re)construção do conhecimento mediado pela aprendizagem baseada em problemas. Rev Bras Enferm. 2014; 67(5): 818-24. https://doi.org/10.1590/0034-7167.2014670521

14. Lunardi VLA. Sansão Normalizadora e o Exame: Fios Visíveis/Invisíveis na Docilização. In: Waldow VR, Lopes MJM, Meyer DE, editores. Maneira de Cuidar, Maneira de Ensinar - A Enfermagem Entre a Escola e a Prática Profissional. Porto Alegre: Arte Médica, 1995. p. 79-108.

15. Lima MM, Reibnitz KS, Kloh D, Vendruscolo C, Corrêa AB. Diálogo: rede que entrelaça a relação pedagógica no ensino prático- reflexivo. Rev Bras Enferm. 2016; 69(4): 610-7. https://doi.org/10.1590/0034-7167.2016690406i

16. Pires AS, Souza NVDO, Pena LHGP, Tavares KFA, D'Oliveira CAFB, Almeida CM. Undergraduation in the nursing school: an integrative review of literature. Rev Enferm UERJ. 2014; 22(5): 705-11.

17. Gomes AMT, Oliveira DC. O núcleo central das representações de enfermeiros acerca da enfermagem: O papel próprio da profissão. Rev Enferm UERJ. 2010; 18(3): 3528.

18. Santos DB, Figueiredo KL, Horta NC. A integralidade e a prática do enfermeiro na estratégia saúde da família. Enferm. Rev. 2014; 17(1): 83-99.

19. Avila LI, Silveira RS, Lunardi VL, Fernandes GFM, Mancia JR, Silveira JT. Implications of the visibility of professional nursing practices. Rev Gaúcha Enferm. 2013; 34(3):102-9.

https://doi.org/10.1590/S1983-14472013000300013

20. Georgiou E, Papathanassoglou EDE, Pavlakis A. Nurse-physician collaboration and associations with perceived autonomy in Cypriot critical care nurses. Nurs Crit Care. 2017; 22(1): 29-39.

https://doi.org/10.1111/nicc. 12126

21. Gomes AMT. A autonomia profissional da enfermagem em saúde pública: um estudo de representações sociais. Dissertação [Mestrado em Enfermagem] - Faculdade de Enfermagem da Universidade do Estado do Rio de Janeiro; 2002.

22. Santos ÉI, Gomes AMT, Marques SC, Ramos RS, Silva ACSS, Oliveira FT. Estudo comparativo sobre representações da autonomia profissional elaboradas por estudantes de enfermagem iniciantes e concluintes. Rev. Latino-Am. Enfermagem. 2017; 25: e2927. http://dx.doi.org/10.1590/1518-8345.1919.2927

23. Gomes AMT, Oliveira DC. Estudo da estrutura da representação social da autonomia profissional em enfermagem. Rev. Esc. Enferm. USP. 2005; 39(2): 145-53. http://dx.doi.org/10.1590/S0080-62342005000200004

24. Santos ÉI, Alves YR, Gomes AMT, Silva ACSS, Mota DB, Almeida EA. Social representations of nursing by non-nursing health professionals. Online Braz J Nurs. 2016; 15(2): 146-56.
25. Dellaroza MSG, Tada CN, Haddad MCL, Vannuchi MTO, Maziero VG. O ensino de gerência em enfermagem na graduação: uma revisão integrativa. Semina: Ciências Biológicas e da Saúde. 2015; 36(1):149-58. https://doi.org/10.5433/1679-0367.2015v36n1Suplp149

26. Farah BF, Dutra HS, Sanhudo NF, Costa LM. Percepção de enfermeiros supervisores sobre liderança na atenção primária. Rev Cuid. 2017; 8(2): 1638-55. http://dx.doi.org/10.15649/cuidarte.v8i2.398

27. Santos EI, Alves YR, Gomes AMT, Silva ACSS, Mota DB, Almeida EA. Representações sociais da enfermagem elaboradas por profissionais de saúde não enfermeiros. Online Braz J Nurs (Online). 2016; 15(2): 1-15. https://doi.org/10.17665/1676-4285.20165294

28. Gomes AMT. O amor na enfermagem: uma aproximação a partir de Platão. Rev enferm UERJ. 2015; 23 (4): 441-2. https://doi.org/10.12957/reuerj.2015.19277

29. Silva RC, Finamore EC, Silva EP, Barbosa VJ. O papel do enfermeiro como educador e pesquisador, e a integração entre prática baseada em evidências e educação permanente. Percurso Acadêmico. 2015; 5(10): 417-30. 